\title{
Vulnerability and coping mechanism: A case study of informal (tea) stalls in public places of Dhaka city.
}

Ishika Alim, Dhaka, Bangladesh.

Affiliation: University of Stuttgart, Faculty of Architecture, Institute of Urban Planning and Design $^{1}$

\begin{abstract}
Informal street vending in South Asian countries - despite having a significant role in building the socio-cultural landscape, are subjected to various degrees of vulnerabilities. This eventually results in threats to their existence and livelihoods associated with it. Especially, amidst the Covid-19 pandemic, the vulnerability of such spaces and the vendors surfaced as an alarming phenomenon. This paper uncovers the vulnerability of the tea stalls, a widely existing type of street food stall in Dhaka city, with a view to identifying the assets the vendors have at their disposal to ameliorate the vulnerability. The research found that the livelihoods of the vendors are politicized by various actors which eventually turns the public spaces into a contested area. The hierarchical relation with these actors does not only create a barrier to community bonding but also affects the asset management of the vendors - making them prone to economic vulnerability. The paper also recommends immediate measures, both spatial and operational, to slow down the poverty slide of these marginalized people due to the Covid-19 lockdown. Drawing upon the findings, an 'iceberg model of vulnerability' is proposed to understand the underlying vulnerabilities of the research community and to uncover the gaps prevailing at the institutional level.
\end{abstract}

\section{Keywords}

informality, street vendors, vulnerability, coping mechanism, Dhaka, Bangladesh

\footnotetext{
${ }^{1}$ this research was conducted in the frame of a master thesis within the program MSc Integrated Urbanism and Sustainable Design (IUSD), University of Stuttgart, Germany.
} 


\section{Introduction:}

The focus of the research, which started with an endeavor to understand the informal spaces - tea stalls, as a condition and catalyst for social coexistence and interaction, took a shift after the Covid-19 breakout and following the drastic impact it unleashed on the life and the livelihoods of the vendors. For this case study, the tea stall has been placed as a widely existing module representing other informal food stalls in Dhaka's street.

The estimated number of street vendors in Dhaka, as of 2010, is 500,000 (Eztold, 2013). This entire population operates their daily business in the street by surviving different vulnerabilities that eventually project threats to their existence. Especially, the Covid 19 pandemic added new dimensions to the vulnerability of this large number of people that needed to be looked at immediately to forecast, prevent and mitigate future threats. Vulnerability study has been an essential foundation for urban risk management for a safe and resilient city. Therefore, the research tries to get a deeper understanding of the vulnerability of the street vendors to mitigate the existing and future risks by identifying their assets and the gaps in the system.

The structure of the paper is divided into three major parts.

The first part gives an insight into the contextual aspects. Followed by addressing the problem statement, research questions, and objectives.

The second part is divided into two sections. The first section uncovers various theories of vulnerability and its components. Drawing upon the theories that correspond with the context and the collected data, the conceptual framework used for the analysis is constructed. The second section emphasizes the methodological approach for the research, data collection, and analysis methods.

The last part discusses the findings, possible future threats and unfolds the 'iceberg model of vulnerability'. To conclude, the paper discusses the possible recommendations highlighting the immediate response against the Covid-19 crisis.

\section{Part I}

\section{Background}

According to the world bank, Dhaka receives 300,000 - 400,000 new migrants each year (Baker, 2007). Most migrants come from rural areas in search of the many opportunities the city can offer for improved living standards. A large portion of these migrants find their livelihoods on the streets. According to research carried out by the Bangladesh Chinnomul Hawkers Shamity ${ }^{2}$ in 2005 estimates 130,000 vendors working within Dhaka City. However, a drastic increase in the number was recorded in 2010 that estimates 500,000 vendors active in the Dhaka area (Eztold, 2013) indicating it is not just a marginal but a vital option for urban labor relations.

3 Bangladesh Chinnamul Hawkers' Samity is a non-profit, non-government organization working for the street vendors' rights and rehabilitation. They have kept a record of the vendors working in Dhaka and are involved in various capacitybuilding initiatives. Here the terms 'Hawkers' stand for street vendors, who sell almost all kinds of everyday necessary items including street food, tea stalls, garments, etc. 
Despite being proclaimed illegal by law (Pure Food Ordinance, 1959; Dhaka Metropolitan Police Ordinance, 1976; Dhaka City Corporation Ordinance, 1983), the sale of food in public places has been tolerated to some extent by the authority. However, the ambiguous status and the absence of proper and integrated policy make the public space of Dhaka a breeding ground for exercising power, extortion, and corruption when it comes to street vending. As a result, these spaces keep altering, keep being appropriated (both physically and socially), or being squeezed down into non-existence when failing to adapt to the 'local field of power structures.'

Acknowledging the social, economic, and cultural importance of street food vending remarkable changes have been adopted in neighboring countries like Singapore, Indonesia, India (Graff 2015, Bhowmik, 2012). Unfortunately, in the context of Bangladesh, this sector is still neglected. Also, this 'traditional' sector is often seen as the marker of poverty which challenges the modernist vision of the state (Broomley,2000). Additionally, keeping up with the global trend, the aspiration to create 'smart cities' often results in frequent and unplanned evictions of these informal stalls. Especially during the Covid 19 pandemic, the vulnerability of these places and the vendors surfaced as an alarming phenomenon.

In a country where the informal sector accumulates almost $90 \%$ of the economy and street food being a major share of it, the economic and socio-cultural importance of street vending needs to be taken into immediate consideration. Otherwise, these micro-social hubs-the critical social outlet in this densely populated city and the means of livelihoods of thousands will perish, so will the unique form of micro public space that the dwellers of Dhaka are accustomed to.

Aim

It is expected that understanding the different degrees of vulnerabilities of these spaces and the implication it has on the socio-spatial, operational and institutional framework, will help understand the assets the vendors have at disposal to mitigate the vulnerability from a community strengthening' vantage point. Also, to track down the gaps prevailing at the institutional level and find out the possible entry points for egalitarian solutions to secure their livelihoods.

\section{Research Objective:}

1. Understanding different degrees of vulnerability and their dynamics in operating the tea-stalls in an urban area.

2. Unfolding the physical and social implications of the vulnerabilities and the responses of the vendors in order to survive and operate their business in a public arena.

3. Constructing an asset portfolio and find entry points for improvement at both community level and in policy level.

\section{Research Question:}

1. How do different degrees of vulnerabilities shape the operational methods, the production of spaces, and livelihoods through Dhaka's informal tea stalls? 
2. In what way does the social and the physical asset management by the tea sellers affect the vulnerabilities and vice versa.

\section{Part II}

\section{Theoratiical departure:}

The research proceeds with understanding what vulnerability is and uncovering its components. Later it tries to construct an approach to understand social vulnerability underpinning livelihoods and institutions, particularly in an informal urban context.

The concept of vulnerability emerged over four decades ago based on the geography and natural hazards research discipline. However, rapid urbanization presented new challenges, making urban residents more vulnerable to dynamic and adverse conditions. Therefore, vulnerability can no longer only be attributed to the environment but should also extend to the economic and social connections and corporations.

According to Moser's asset vulnerability framework, in the urban context, vulnerable communities were found to be less dependent on natural resources and more on labor power, housing assets, and social connections (1998). Therefore, an individual's capacity to cope with vulnerability under the exposed risks is intensely determined by the outcome of complex social relationships, networks, and interaction processes. According to her framework, this 'social capital' thrives in reciprocity within communities and households based on trust deriving from social ties. She implied that the critical relationship between vulnerability and asset ownership provides an important direction to the operational significance. In line with Sen (1981), Swift (1989), Maxwell, and Smith (1992), she asserts that vulnerability comes hand in hand with resilience and responsiveness, in resisting and recovering from it by using the 'assets'. Therefore, the greater and dynamic the asset is, the less prone an individual is against the vulnerability.

Moser's theory intensely focuses on the innate capacity building of the vulnerable and does not address issues of politics and governance - core components of urban informality. Other theorists (Watts and Bohle 1993, Fineman 2008) have stressed the importance of the political and power dynamics as a prime catalyst to understanding risks and vulnerability.

According to Watts and Bohle (1993), the space of vulnerability is determined by the political, economic, and institutional capabilities given specific places at specific times. Their 'tripartite casual structure' of vulnerability is formed by intersecting three sides- entitlement, empowerment, and political economy, which determine the exposure, capacity, and potentiality. Therefore, the socio-economic basis and practices of livelihood relate to issues of access and institutional entitlement.

Bohle asserts, vulnerability is located in the sphere of economic and social relations, especially in market relations and social networks where entitlements are produced and reproduced, and where access to entitlements is determined under conditions of violence (2007). Therefore, if the access deprivation resides in the powerlessness of individuals, classes or groups - to claim and enforce livelihood entitlements, then vulnerability is determined by the power relations and institutions. Though the theory was provided for femine and food security, it combines the politics of access and entilements which is crucial to urban context and in informality dynamics. In this sense, in an urban setting where 
vulnerability is largely regulated by the actors and social institutions, Fineman argues that state must accept the responsibility for the ,effects and operation' of those institutions (2008). Fineman points out that the state must provide equal access to the 'societal institutions' - that distributes the social goods such as health care, employment and security. Unlike Moser's theory, Fineman's theory of vulnerability does not explain methods of resource allocation among vulnerable individuals, but asserts that vulnerability may be a viable basis for policy intervention.

Finally, the frame (figure 1) that has been suggested here for understanding the urban risk and vulnerability of informal modes of livelihoods connects diverse debates underpinning innate capacity building with those about urban politics and modes of governance. Analyzing the two fields rather than separating them, I argue, generates new insights about the vulnerability of informal settlements in urban vicinity. Using the 'space vulnerability' theory by Watts and Bohle, this part subsequently tries to draw a relation between two other theories - Caroline Moser's (1998) asset vulnerability framework (building upon community's innate potential) and Martha Fineman's theory of vulnerability (2008). While Watts and Bohle's theory gives an overview of the forces of space vulnerability and its connection with livelihood framework, the latter two theories help understand how the management of assets affects the livelihoods from a bottom-up approach and how vulnerability becomes a tool for defining the appropriate role of government.

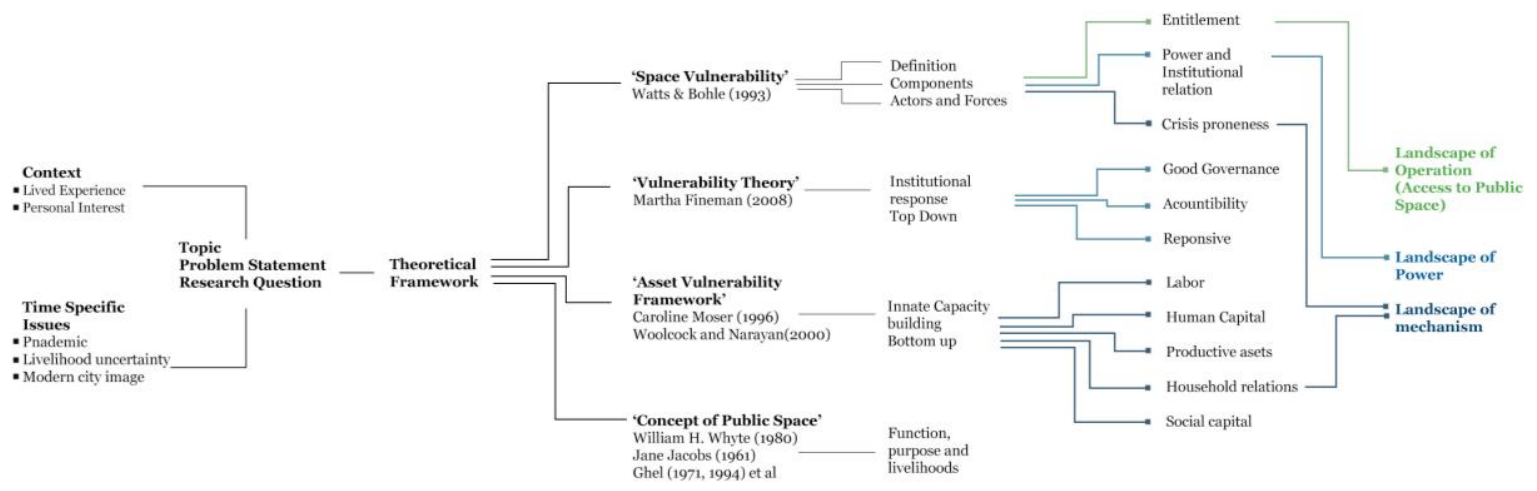

Figure 1: Theoratical Framework for the vulnerability study, Source: Author'20

\section{Framework and Conceptualiztion}

Fore the case study of Dhaka tea stalls, Watts and Bohle's 'space of vulnerability' (1993) framework has been contextualized based on the empirical findings. The fundamental relational nature of the space vulnerability concept can be identified through three realms. Contextually these three realms are, the field of power (empowerment), the field of operation (entitlement) and the field of mechanism (crisis peoneness). The field of power represents the relations between the government, non-government and informal modes of governance, thus highlights the power relation. It uncoveres the role of social and political networks in catalysing agency and access. This formulates the second realm of vulnerability 'the field of operation' underpinning the politics of access and entitlement. The field of operation represents the arena where all these forces are at play - 'the public space', where all the physical expression and 
manifestation of these negotiations take place. The third component, 'field of mechanism' represents the adaptive capacity which is influenced by the management of the assets of the vulnerable group to overcome the situation. Each of the components, forces, and exposure determine the outcome vulnerability-the potential net impact. Which, in this case are the livelihoods, income, and health.

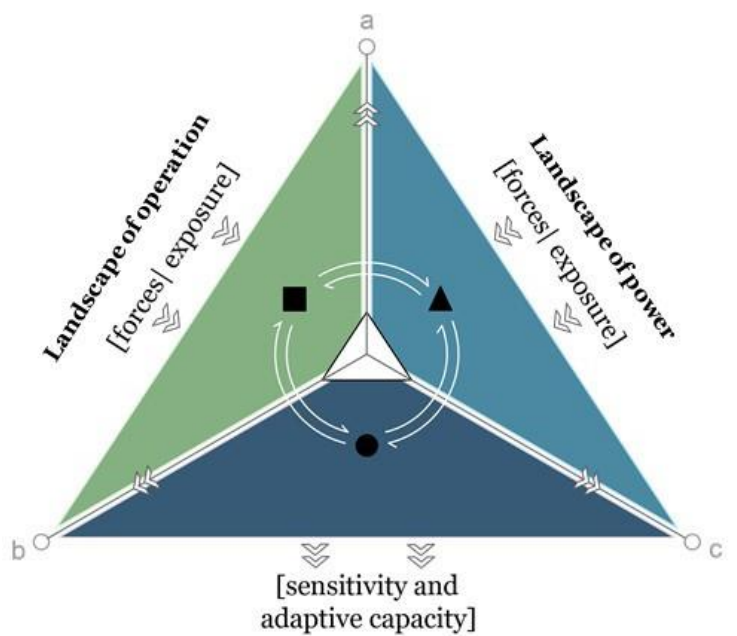

Landscape of mechanism (a) livelihoods (b) income (C) health $\triangle$ space of vulnerability

Vulnerability as entitlement

Vulnerability as powerlessness

vulnerability as social relation of production

space ofvulnerability

Figure 2: Conceptualization and contextualization of Watts and Bohle's model of space vulnerability in the context of Dhaka (modified by author, 20)

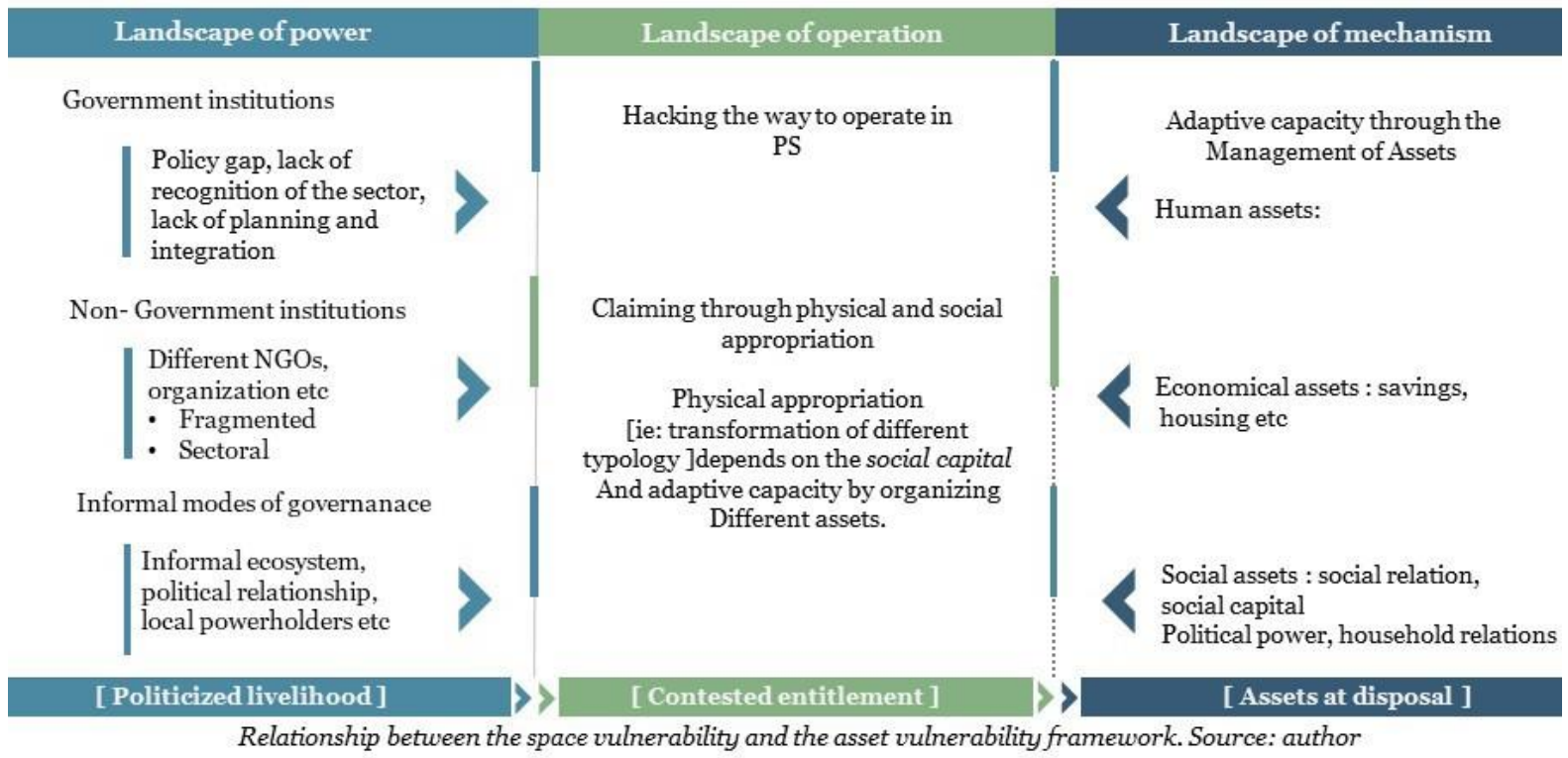

Figure 3: Framework to determine relationship between three realms of 'space vulnerability and the topics associated with each realm. Source: Author'20 


\section{Methodology:}

\section{Approach}

Since vulnerability is a multi layered socio-political construct, the research takes a qualitative and explorative approach to form a deeper understanding of the topic. The research followed an iterative process of data collection and literature review to address the dynamic nature of vulnerability.

\section{Data collection}

Given the pandemic on-ground, empirical study was not possible to conduct. Therefore, the research largely depended on secondary data, gray literature and open sources. Intensive review and analysis of newspaper articles (nos 25) were done to track down the vulnerabilities. Additionally, online survey was conducted to collect data from the users and stakeholders. Being one of the most vulnerable groups to be affected by the pandemic, from a moral and ethical point of view, the vendors were not approached for interviews. However, semi-structured interview over the phone with three vendors was made possible to conduct during a later period of time. Although the sample is small, the interviews shed light on crucial findings during the pandemic.

\section{Analysis}

All the compiled data were repeatedly reviewed and tagged with codes. As bulk data were collected, they were reviewed, coded, and regrouped. For an instance, using the word search process, such as 'vulnerable', 'eviction', 'extortion' etc - findings were categorized according to 'vulnerability, actors, positive remarks, negative remarks, coping strategies, etc. Thus, the initial and primary identification of the vulnerabilities were jolted down. Also, different coping mechanisms against the vulnerability and newly emerged vulnerability due to the pandemic were identified through interviews and were later connected with respective assets based on the framework. Theories were revisited, and new theories were explored in the process to better conceptualize them.

\section{Limitations}

Given all flights were canceled two weeks before the field research, on-ground empirical study could not be conducted. However, being locked up in Germany provided enough time to reflect on the situation and to form a deeper understanding to address the unprecedented crisis that we were facing. Therefore, substantial time was spent to rethink the topic and restructure the entire research. Additionally, reaching out to the main stakeholders and the research community from abroad proved to be difficult and timeconsuming.

\section{Part III}

\section{Findings:}

Based on the collected data, five types of vulnerabilities were found - eviction, extortion, lack of services and infrastructure, unprecedented situations, and economic stress. However, these vulnerabilities were

\section{U isocarp}


found to be the by-product of different actors, forces, and locations. Therefore, based on the conceptual framework, a deeper understanding of the causes and forces of the vulnerabilities are explored.

\section{Landscape of power}

The research found that access to public space is not free and is controlled by various formal and informal bodies. Hence, turning it to be a contested space. For the sustenance of their livelihoods, the vendors are forced to establish different forms of association with the formal and informal actors active on the ground. The nature of this network impacts social capital. Based on the relationship dynamics, regulated by trust. Linking, bridging, and bonding (Woolcock and Narayan 2000) are the types of networks that are established with different actors. In the context of Dhaka city, three categories of actors were underpinned - state institutions, non-governmental institutions, and agents of informal relation.

In informal street business in Dhaka, local forces were mostly visible and appeared to have larger power and control over the public space. It was also found that the informal agents have direct or indirect connections to the formal or state actors (Chowdhury, 2009). On the contrary, the formal agents were also found to be connected with informal modes. Therefore, the boundaries between the formalinformal get blurred.

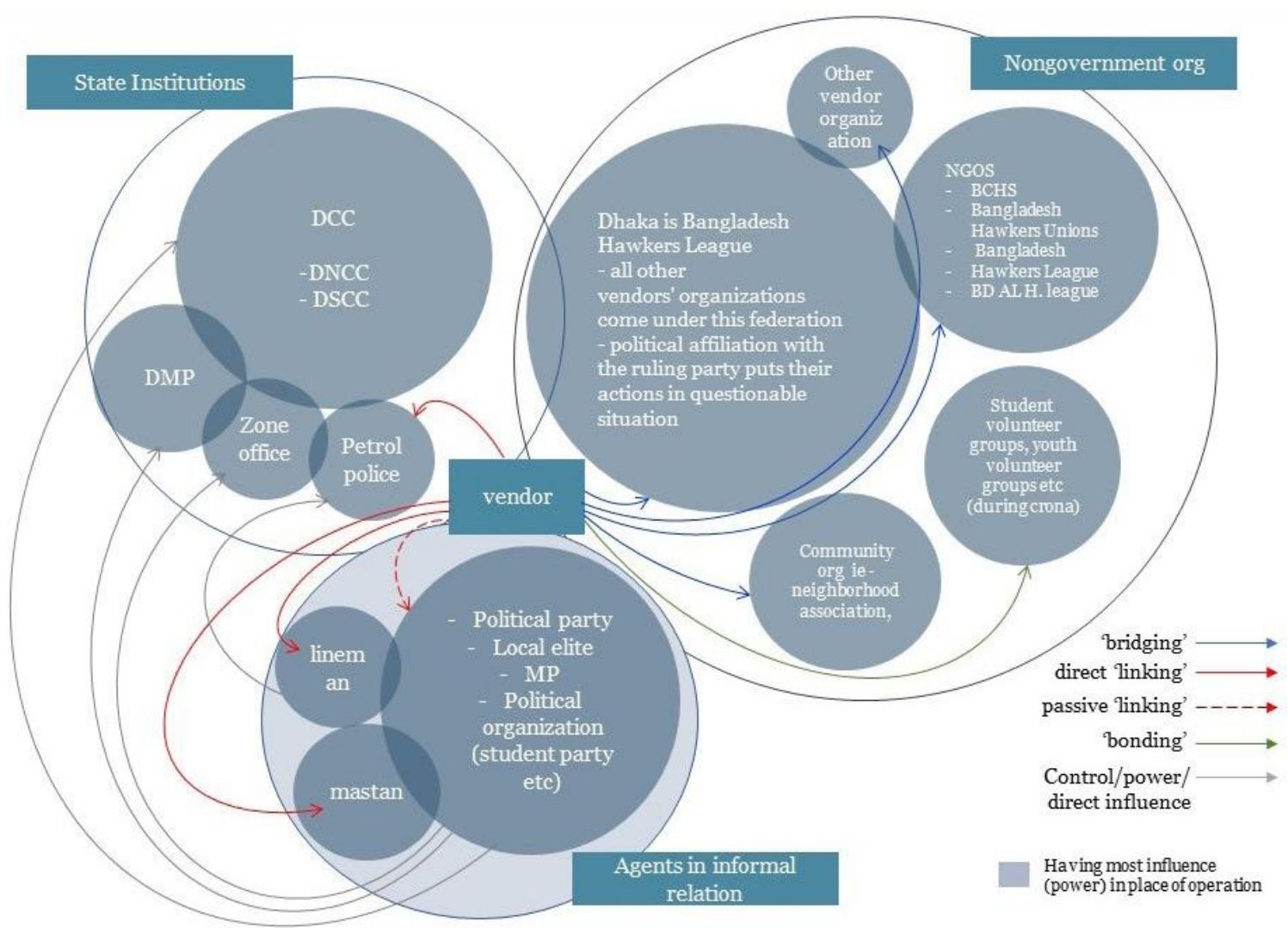

Figure 4: Power actors and the type of relation the vendors establish with them for survival. Source:Author'20

The space of vulnerability is directly and indirectly regulated by these formal and informal agents in power. In his study of Dhaka's food vendors, Etzold (2013) found that those who complied with the demands of police and mastans, acting for local politicians, and paid protection money, enjoyed regular and exclusive access to public space. Formal and informal actors were mostly found to be related to 
political power holders, making it impossible to have collective resistance against such powerful forces ${ }^{3}$. Although the NGOs and organizations have limitations from operating in any political capacity, the existing vendor associations in Bangladesh have been found to be thoroughly subordinated to the ruling party ${ }^{4}$. This raises a trust issue among the vendors agains the non-government organizations and party contributes to the reason why the organizations have not succeeded in forming a collective resistance from the community against the extortions.

\section{Landscape of operation}

Although vendors are not usually equipped with conventional sources of power, they use locationspecific tactics to circumvent restrictions and maintain their businesses (Duneier 2000; Stoller 2002). This can be understood by the typology and the transformation of the stalls over the period of time as a response to the perceived threats (figure 5). Dhaka's food stalls can be divided into four main typologies based on the structural capacity- permanent, semi-permanent, semi-mobile, and truly mobile. Apart from various appropriation methods to survive different degrees of vulnerabilities, one major tactic is to shift between typologies. However, substantial relation between the typology and income was found through the research (figure 5). Based on the savings per day, and the international poverty line ${ }^{5}$, the typology can be categorized as non-poor, vulnerable non-poor, and extreme poor consecutively to permanent, semi-permanent, semi-mobile, and mobile vendors (figure 6). However, during the pandemic the permanent and semi-permanent shops remained closed and a large portion of the migrated mobile vendors went back to the villages. The tactics that the permanent and semi-permanent vendors adapted was to move to a more mobile typology and take up home delivery in some cases. They started selling tea in a flask and roamed around the city selling tea and snacks. Those who were physically incapable, made their children roll into the business for survival. As we have already seen that the typologies are associated with income, thus typologies correspond with the poverty line (figure 7). This prolonged uncertain situation, made the non-poor slide down the poverty ladder into vulnerable poor non-poor, the vulnerable non-poor to the new poor, and the poor to the extreme poor. Therefore, it is certain that not just the pandemic but any other forces causing a prolonged hindrance to the vendors' livelihood will ultimately cause them to slide down the poverty ladder. This interdependency and the spatial relation with the income presents an important dynamics of spatiality of livelihoods.

\footnotetext{
${ }^{3}$ The initial setting up of a tea stall usually requires having a good 'linking' with these informal agents such as the local lineman (A lineman is an individual who collects security money from hawkers and vendors and distributes it to other groups; such as police, local thana), mastans (local youth who is employed/'used' by powerful leaders, for example to organize election campaigns) or other political power holders to acquire a space for their business (interview, 2020). The mastan or local enforcer is a well-known figure among the poor in Bangladesh. He provides a direct link between the political elite and the underworld (Chowdhury, 2009). Mastans act on behalf of the powerful and politically connected, as the human face of extortion, collecting bribes, fees and other commissions from the poor on behalf of local powerbrokers.

4 'Dhaka Bangladesh Hawkers League' claims that all other vendors' organizations come under this federation. Though this is claimed to be a non-governmental organization, it's political affiliation with the ruling party puts their actions in questionable situation regarding trust-based networking from the vendor's side. It is also interesting to notice how a new organization name was evolved 'Dhaka Bangladesh Awami-league Hawker's league' being specifically associated with the ruling party Awami-league. This associations are mostly run by the political power holders, youth and locals holding political power representing the ruling party.

${ }^{5}$ World Bank's international poverty line is USD1.90/day, as of 2011. The standard of 1 dollar a day was first proposed in 1990 for measuring absolute poverty by the standard of the world's poorest countries. Tk stands for Bangladeshi currency, $1 \mathrm{USD}=85.21$ taka.
} 


\begin{tabular}{|c|c|c|c|}
\hline $\begin{array}{l}\text { Consolidated and semi } \\
\text { consolidated stalls }\end{array}$ & semi permanent stalls & semi mobile & Truly mobile \\
\hline $\begin{array}{l}\text { To keep a claim despite } \\
\text { the evictions. strategy is to } \\
\text { transform the shop into } \\
\text { more temporary structure, } \\
\text { lowering visibility } \\
\text { Simply closing the stall } \\
\text { during such threats } \\
\text { Capitalizing on social } \\
\text { relation with the power } \\
\text { brokers .etc } \\
\text { Represents better relation } \\
\text { with the local power } \\
\text { structure, better income }\end{array}$ & $\begin{array}{l}\text { Availing information from } \\
\text { the local lineman and } \\
\text { closing the stall before } \\
\text { such threat } \\
\text { More permanent the shop } \\
\text { is, represents more the } \\
\text { power and local alliances } \\
\text { he has at disposal }\end{array}$ & $\begin{array}{l}\text { Timing, alliances, relocating, } \\
\text { hiding the stuff }\end{array}$ & Timing, alliances, relocating \\
\hline Daily savings: 780 taka & Daily savings: 300 taka & Daily savings: 300 & Daily savings: 220 \\
\hline
\end{tabular}

Claiming public space through physical and social appropriation ( based on available secondary data and 3 informal interviews with the seller

Figure 5: Typology, survival tactics and income relation. Source:Author'20

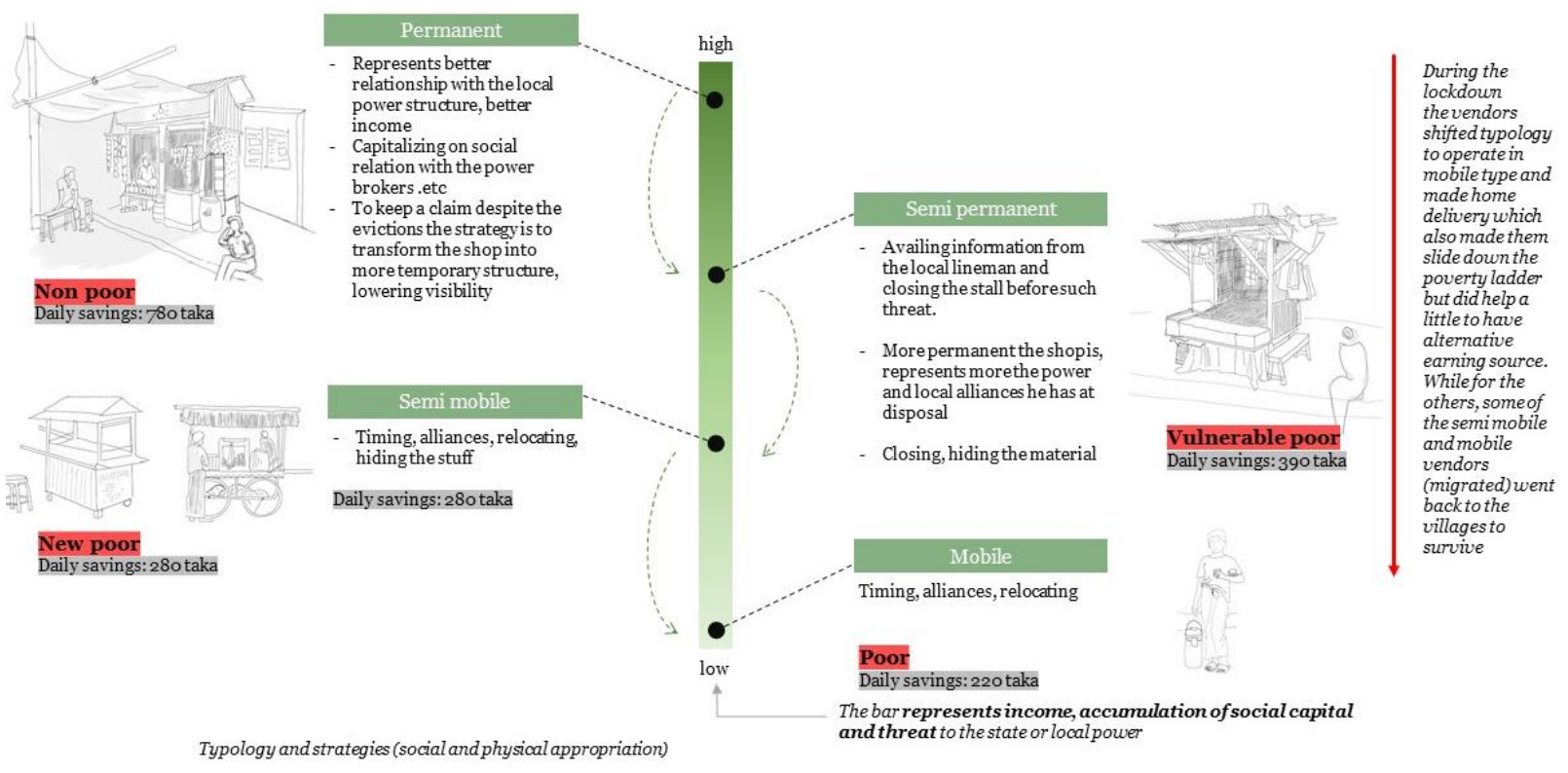

Figure 6: Typology and poverty relation. Source: Author'20

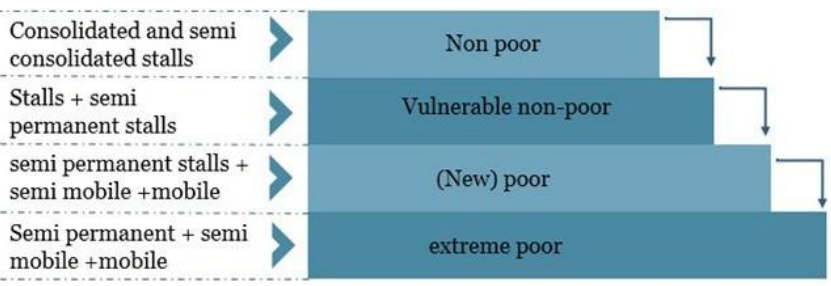

Figure 7: Sliding down the poverty ladder under prolonged unprecedented situation (Covid-19 pandemic in this case). Source: Author'20 


\section{Landscape of mechanism}

Here, Drawing upon Moser's five types of assets - Labor, Human capital, Productive assets, household relations, and social capital, an attempt to construct an asset portfolio has been made based on the findings. While the social capital proved to be the most common and useful asset to cope with the vulnerabilities during the pandemic, 'human capital' and 'labor' as assets were found to be the most vulnerable due to the health risk and the economic downfall.

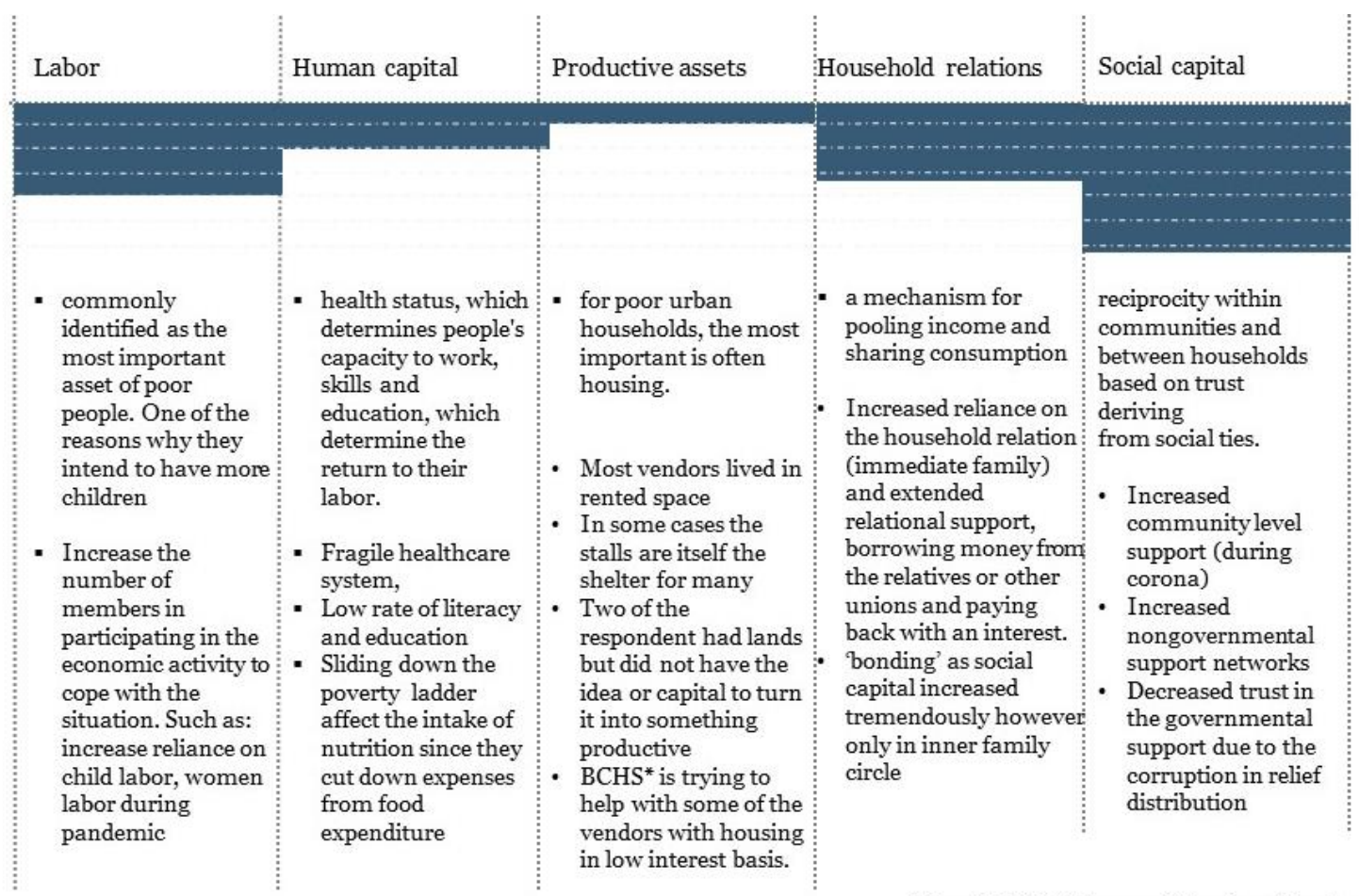

*Bangladesh Chinwamul Hawkers Shamity

Figure 8: Typology and poverty relation. Source: Author'20

\section{Part III}

\section{Discussions :}

It has been noted through the interviews that the vulnerability concerns of the vendors changed during the pandemic compared to the concerns that they had before (figure 9. During the Covid-19 pandemic and new vulnerabilities emerged indicating future vulnerabilities. Therefore the vulnerabilities are interrelated to time and season. It was also found that the vulnerabilities can shift given different times and different situations (figure: 9).

The research also found that vendors, based on the location and the nature of the vulnerability, rely on different coping mechanisms. Some of these coping mechanisms result in triggering new form of vulnerability. Such as, the eviction drive, may result into relocation which eventually could trigger economical vulnerability. On the other hand, relocation is a coping mechanism to escape eviction or extortion, which also makes them economically vulnerable by reducing the income due to loss of clientele. 


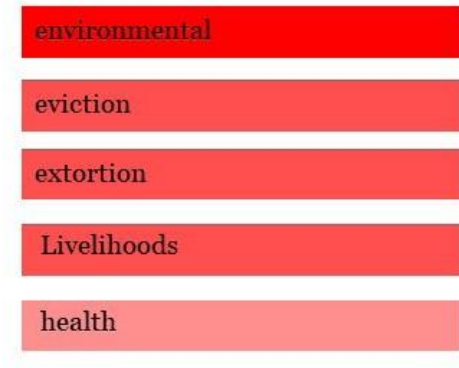

Before the Pandemic

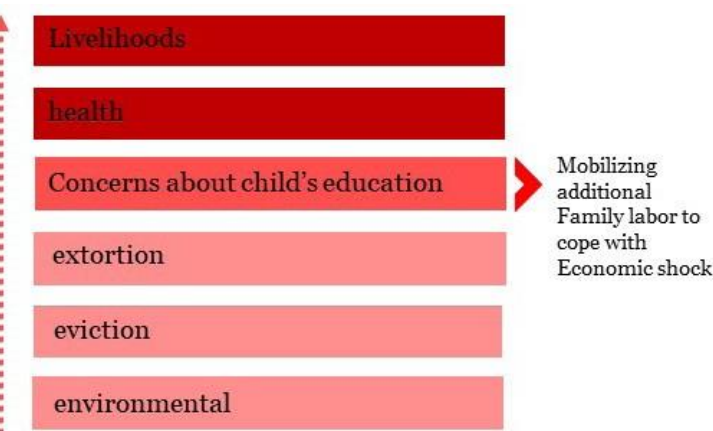

During the Pandemic

Figure 9: Typology and poverty relation. Source: Author'20

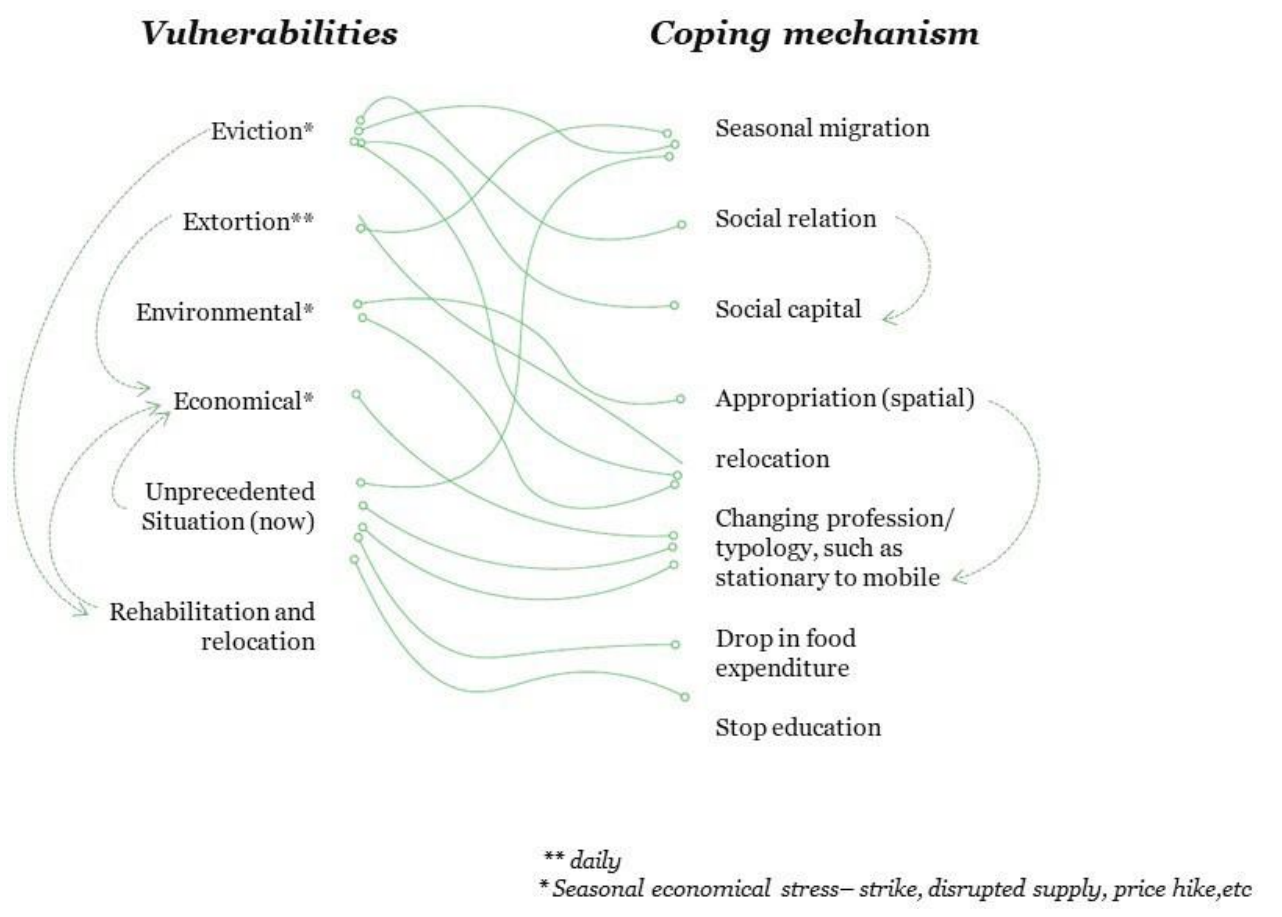

Figure 10: Shifting vulnerabilities and shifting coping mechanisms. Source: Author'20

\section{Implications}

Based on the findings, the research asserts that the political arena of street vending in Dhaka has cascading impacts which makes the vendors vulnerable to various situations. The implications are as follows -

- Restricted access - As long as this patronizing power structure remains the public space will not be free from their control. This rigid control can only be diminished by incorporating accountability from the top down.

- Personalized relation and Hierarchy - vertical linking with the powerful actors for mutual benefits and obligation are constructed between unequal individuals. Through this link, 
negotiations around access to resources, protection, social mobility and political support take place.

- Declining trust-based relation - such vertical relationships are not only asymmetrical and personal but also uncertain since they remain discretionary rather than formalized or rightsbased. This 'linking' social capital is based on only mutual benefit but not on trust (as some actors are involved in extortions and voilence )

- Lack of lateral bond - This personal transaction between two interested individuals is opposite to collective good. This personalized quality is a key reason why it remains difficult for vendors to build 'horizontal' relationships of solidarity among equals.

- Barrier to Organizational Initiative - Despite numerous Organizations working on ground, the situation has merely changed due to this power structure and the personalized beneficial links. Also, political affiliation of some organizations puts all other in questionable state and thus vendors find is difficult to extend trust based relationship. Therefore they bridge out to them.

This becomes even more crucial when a particular vulnerability persists prolonged time. In this case, the cascading impact of a prolonged vulnerability - Covid-19 and its projected possible future threats are noted as follows-

- Loss of livelihoods due to access restriction.

- Huge health risk due to lack of health care, lack of awareness and also due to vendors' resuming their operation violating the lockdown measures.

- During the pandemic newly emerged poor and extreme poor need to be supported immidiately to slow down the poverty slide. Otherwise, there is a risk of them becoming net borrowers.

- To survive the economic shock increase in child labor as mobile vendors was noted. If the situation remains the same, they will continue to be on this path causing a large number of children to drop off school to help out their families. This colossal damage to children's education will ultimately cause a human capital crisis in future.

\section{The Iceberg Model: gaps in two folds of vulnerability and possible recommendation}

Five major vulnerabilities were identified which created a barrier for the vendors from operating in a public space and that shifted during different times. These vulnerabilities are - eviction, extortion, lack of service and infrastructure, unprecedented situation, and economic stress. However, the research asserted that these are only the tip of the iceberg that is actually the result of deeper underlying vulnerabilities. Since the strong political forces and agents are controlling the public space, at the same time extorting the asset portfolio of the marginalized community, immediate grassroot movement cannot be expected from the community. Furthermore, since most of the institutions were found to exercise their state-given power to extort others, the state must take responsibility for the 'effects and operation' of these actors (Fineman, 2008). The illegal power play and extortion can be ameliorated by taking strict action, record keeping, and imposing accountability in a top-down manner. On the other hand, the contested public space can be taken into consideration and solved with spatial planning and distributing spatial rights to the vending community. 
top down approaches to ensure safe environment for vendors

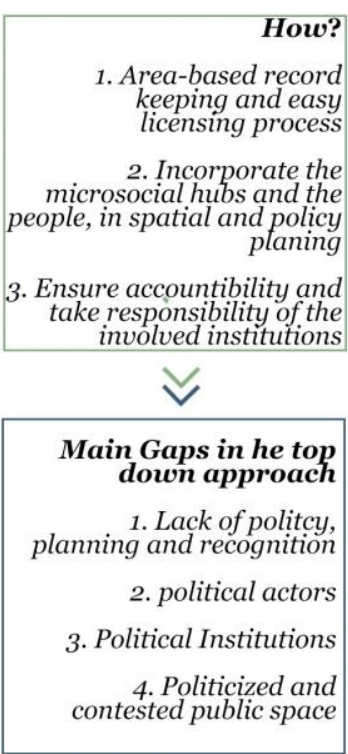

Acess to public space

Entitlement

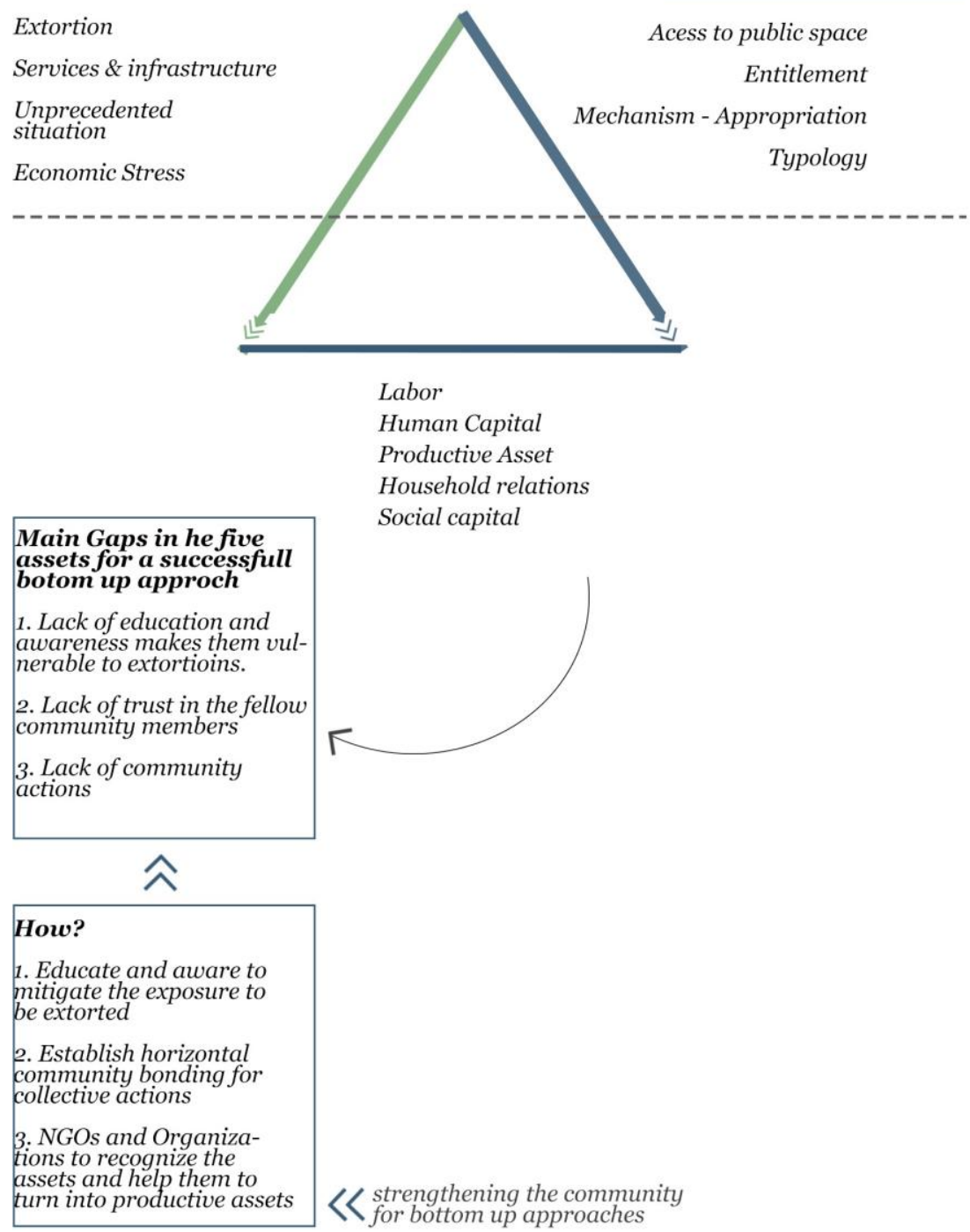

Figure 11: Icebeg model for vulnerability of the tea vendors in Dhaka city and the gaps in top down and bottom up approaches. Source: Author'20 
While the tip of the iceberg and the actors needs to be tackled using a top-down manner, the bottom of the iceberg needs focusing on building the innate capacity of the community. The underlying reasons for the vendors being vulnerable to such politics, contestation, and failing to make a collective resistance were found to be the outcome of lack of awareness, lack of education, and lack of trust in the community. Here, bottom-up initiatives involving the local community and the organizations can play a vital role in building up the community's innate capacity.

Given the type of space vulnerability, the vendors are subjected to, and given the highly politicized nature of the public space, only top-down or only bottom-up interventions alone will not result in effective policy planning. Gaps in both ends need to be filled simultaneously for an egalitarian and long-term effective result.

\section{Recommendation}

\section{Immediate response:}

The research finding indicates that immediate measures need to be taken for the ultra-poor and the newly emerged poor to impede further future crises. Emergency food support and access to health care need to be provided immediately. Given the corruption, the last mile delivery also needs to be addressed in collaboration with the local organization to ensure effective distribution. Moreover, resuming livelihood activities in public spaces ensuring safety measures and health regulations need to be implemented with proper spatial planning and expert involvement. Such measures and spatial planning to resume street vendors' operation in public space gained popularity in Myanmar (Nyein, 2000) during the pandemic.

\section{Long term response:}

\section{Registration, recognition and social security}

The registration of the street vendors can generate substantial revenue for the state. Also, this recordkeeping can help in the future to quickly identify the most vulnerable and extend relief/help according to their requirement. Legalization might help to change the way authority look at these informal spaces, but this will impact the self organizing and organic nature that makes it unique and make vendors vulnerable to informal practice of patronage and furtherextortions

One of the most important actions would be to integrate such spaces with spatial design and policy. Reformation of the existing spatial policies and adding new regulations that fit with the demand, time, and context is crucial. The access to public space needs to be made inclusive based on the feedback and engagement of the vendors, users, and stakeholders.

Besides, given the high saturation of street vendors, alternative livelihood options need to be provided by identifying the skillset, enhancing them with vocational training in collaboration with the NGOs.

To conclude, Further research should be done to understand the hotspots and geographical locations of these vulnerabilities and incorporate these spaces in terms of both policy and spatial planning of the city.

Intensive spatial and social research can also be conducted to understand how these micro-social hubs operate in meeting the demands and needs of the urbanites and the vendors on a daily basis. This would help to emerge multitudes of new archetypes based on context-specific best practices that can further support the dwellers with their need for public space in the densely packed city. 
Alim, I.

\section{References:}

Baker, J. L. (2007). Dhaka: improving living conditions for the urban poor. Bangladesh Development Series, paper no 17.

Bhowmik, S. (2012). Street vendors in the global urban economy. Taylor \& Francis.

Broomley, R. 2000, Street Vending and Public Policy: A Global Review, International Journal of Sociology and Social Policy,

Bohle, H. G. (2007) Geographies of Violence and Vulnerability. An Actor-Oriented Analysis of the Civil War in Sri Lanka,

Chowdhury, A. I. (1992). Urban Land Market in Dhaka. In Islam, N. and Chowdhury, A. I. (Eds.), Urban Land Management in Bangladesh, Dhaka: Ministry of LAND,115-22

Duneier, M. 2000. Sidewalk. New York: Farrar, Straus and Giroux.

Etzold, B., Hossain, M. A., and Rahman, S. (2013). Street Food Vending in Dhaka: Livelihoods of the Urban Poor and the Encroachment of Public Space

Fineman, M. A. (2008) The Vulnerable Subject: Anchoring Equality in the Human Condition, Yale Journal of Law \& Feminism

Graff, K., \& Ha, N. (Eds.). (2015). Street vending in the neoliberal city: A global perspective on the practices and policies of a marginalized economy. Berghahn Books.

Maxwell, S. and Smith, M. (1992), "Household food security: A conceptual review" in S. Maxwell and T. Frankenberger(Eds.) Household Food Security: Concepts, Indicators, Measurements, (Rome and New York: IFAD and UNICEF, 1992).

Moser, C. (1996), Confronting crisis: A comparative study of household responses to poverty and vulnerability in four poor urban communities, ESD Monograph No. 8, May. The World Bank, Washington, DC.

Moser C. (1998), The asset vulnerability framework: Reassessing urban poverty reduction strategies. World Development 26(1): 1-19.

Nyein, N (2020), Myanmar Town Finds Way to Protect Market Vendors, Customers Amid COVID-19, The Irrawaddy, 28 April, available at: https://www.irrawaddy.com/specials/myanmar-covid-19/myanmartown-finds-way-protect-market-vendors-customers-amid-covid-19.html, (Accessed on: 20 th July 2020)

Sen, A. (1981) Poverty and Famines: An Essay on Entitlement and Deprivation, Oxford: Clarendon Press.

Stoller, P. (2002). Money Has No Smell: The Africanization of New York City. Chicago: University of Chicago Press.

Swift J. (1989), Why Are rural people vulnerable to famine? IDS Bulletin 20(2).

Watts M., Bohle H.J., (1993), The space of vulnerability: The causal structure of hunger and famine. Progress in Human Geography 17(1): 43-67.

Woolcock, M. A., Narayan, D. (2000): Social capital: implications for development theory, research and policy. In: The World Bank Research Observer 15 (2), 225-249. 